\title{
The prevalence of major mental illness, substance misuse and homelessness in Irish prisoners: systematic review and meta-analyses
}

\author{
G. Gulati ${ }^{1 * *}$, N. Keating ${ }^{2}$, A. O'Neill ${ }^{3}$, I. Delaunois ${ }^{4}$, D. Meagher ${ }^{5}$ and C. P. Dunne ${ }^{1}$ \\ ${ }^{1}$ Graduate Entry Medical School, University of Limerick, Limerick, Ireland \\ ${ }^{2}$ Department of Psychiatry, University Hospital Limerick, Limerick, Ireland \\ ${ }^{3}$ Department of Mathematics and Statistics, University of Limerick, Limerick, Ireland \\ ${ }^{4}$ University Hospital Limerick, Limerick, Ireland \\ ${ }^{5}$ Department of Psychiatry, Graduate Entry Medical School, University of Limerick, Limerick, Ireland
}

\begin{abstract}
Aims. To systematically review studies from Irish prisons that estimate the prevalence of major mental illness, alcohol and substance misuse, and homelessness at the time of committal.

Methods. Healthcare databases were searched for studies quantifying the point prevalence for each outcome of interest. Searches were augmented by scanning of bibliographies and searches of governmental and non-governmental websites. Proportional meta-analyses were completed for each outcome.

Results. We found eight, six and five studies quantifying the point prevalence of major mental illness, substance misuse, and homelessness respectively. Considerable heterogeneity was found for each subgroup (except psychosis where substantial heterogeneity was observed) and random effects models were used to calculate pooled percentages. The pooled percentage for psychotic disorder was 3.6\% [95\% confidence interval (CI) 3.0-4.2\%], for affective disorder $4.3 \%$ (95\% CI 2.1-7.1\%), for alcohol use disorder 28.3\% (95\% CI 19.9-37.4\%), for substance use disorder 50.9\% (95\% CI $37.6-64.2 \%)$ and for those who were homeless on committal $17.4 \%$ (95\% CI 8.7-28.4\%).
\end{abstract}

Conclusions. Estimates for the prevalence of psychotic illness and substance abuse amongst Irish prisoners are in keeping with international estimates of morbidity in prisons, whilst those for affective disorders are lower. The prevalence of homelessness in committal to Irish prisons is higher than some international estimates. Rates for psychoses, alcohol and substance misuse as well as homelessness in Irish prisons are significantly higher than the general population prevalence of these vulnerabilities. A need for service development is discussed.

Received 27 October 2017; Revised 13 February 2018; Accepted 3 April 2018; First published online 9 May 2018

Key words: Addiction, homelessness, mental disorder, prison, substance misuse.

\section{Introduction}

There are 10.35 million people held in penal establishments worldwide (Walmsley, 2016). Recent large-scale systematic reviews have established that prisoners suffer multiple vulnerabilities including mental disorder, substance misuse and homelessness. Fazel \& Seewald (2012), in a systematic review of the international literature, found that mental illness is over-represented in prisoners. They identified a pooled 6-month prevalence of psychosis of $3.6 \%$ in male prisoners and $3.9 \%$ in female prisoners. The pooled prevalence of major depression was $10.2 \%$ in male prisoners and $14.1 \%$ in female prisoners. No significant differences in rates of psychosis and depression between remand and sentenced prisoners were identified. The authors

\footnotetext{
* Address for correspondence: G. Gulati, Kilmallock Day Hospital, Kilmallock, County Limerick V35 VP21, Ireland.

(Email: gautam.gulati@hse.ie)
}

further found high levels of heterogeneity in the review, partly explained by higher rates of psychosis in low-middle-income countries. Fazel \& Danesh (2002), in an earlier review of 6-month prevalence data from 12 countries, found that $3.7 \%$ of men [ $95 \%$ confidence interval (CI) 3.3-4.1] had psychotic illnesses and 10\% major depression. Rates in women were $4.0 \%$ with psychotic illnesses and $12 \%$ major depression. Older prisoners, in addition, may have significantly higher rates of affective disorder, with one study reporting a prevalence of $30 \%$ for depressive disorder (Fazel et al. 2001). These prison estimates are significantly higher than international population point prevalence estimates for psychotic illness, which have been reported as 4.6/1000 (Saha et al. 2005) and major depressive disorder reported as $4.7 \%$ (Ferrari et al. 2013).

Suicides are also over-represented in the prison population. A study (Fazel et al. 2011) reviewing data from 12 countries found that in men, crude relative 
rates of suicide were at least three times higher than the general population. Western European countries had similar rates of prisoner suicide, which were mostly higher than those in Australia, Canada and New Zealand. In women, inmate suicide rates varied widely and were raised compared with rates in the general population.

Substance and alcohol misuse are associated with the significant economic burden (Rehm et al. 2006) and are risk factors for offending (Grann \& Fazel, 2004). Their prevalence in marginalised communities such as homeless populations and prisons is of international concern. A systematic review evaluating substance abuse and dependence (Fazel et al. 2006) across 13 prison-based studies, found that estimates of prevalence for alcohol abuse and dependence in male prisoners ranged from $18 \%$ to $30 \%$ and $10 \%$ to $24 \%$ in female prisoners. The prevalence estimates of drug abuse and dependence varied from $10 \%$ to $48 \%$ in male prisoners and $30 \%$ to $60 \%$ in female prisoners. This review excluded studies citing only lifetime prevalence rates. Compared with US general population estimates (Kessler et al. 1994), this review noted that male prisoners have a slight excess of alcohol dependence and a two- to 10-fold excess of drug dependence whilst estimates for female prisoners noted a two to a fourfold excess of alcohol dependence and 13-fold increase in drug dependence.

Incarceration is associated with homelessness, and homelessness can be a cause or consequence of incarceration (McCann, 2003). Homelessness is in itself associated with higher levels of mental illness and substance misuse (Fazel et al. 2008) with both these vulnerabilities affected by trends towards the closure of long-stay psychiatric hospitals or 'asylums' (Paulson, 2012). McNiel et al. (2005) found that $16 \%$ of those incarcerated in the San Francisco penal system were homeless. Greenberg \& Rosenheck (2008), in a national study of US inmates, found that $12.4 \%$ had been homeless in the previous year, although not at the time of incarceration; and $2.9 \%$ were homeless at the time of incarceration. A United States Bureau of Justice Statistics study (Hughes et al. 2001) representing a nationwide survey of state prisoners expecting to be released in 1999, found that $12 \%$ reported being homeless at the time of their arrest. Estimates in the United Kingdom for homelessness at the time of committal are $15 \%$ (Williams et al. 2012).

The Irish Penal Reform Trust (2017) reported that there were 3674 people in prison custody in Ireland as of December 2016, with a rate of imprisonment of 79 per 100000 of the population. The Irish prison population increased by $400 \%$ from 1970 to 2011 . The 14 institutions in the Irish prison system consists of 11 traditional 'closed' institutions, two open centres and one 'semi-open' facility. Female prisoners are accommodated in two prisons nationally. The Irish Prison service (2015) reported of those sent to prison, 79.4\% were male and $20.6 \%$ were female. Approximately one-sixth of the total prison population comprised remand prisoners.

Mental disorder, substance misuse (Council of Europe, 2015) and homelessness (McCann, 2003) have been highlighted as key areas of need amongst Irish prisoners. Whilst the prevalence of these vulnerabilities are studied by health services, governmental and nongovernmental organisations, they have not been systematically reviewed.

Whilst reviews of international literature often report a lifetime prevalence of these vulnerabilities, an analysis of need informing resource management requires estimates of point prevalence - What proportion of prisoners actively suffer from a psychotic, major affective disorder or substance misuse disorder at the time of assessment? What proportion are homeless at the time of committal to prison? This is in contrast to those that have a history of these vulnerabilities, which although relevant to their long-term needs, may be less pertinent when estimating immediate care needs. In this study, we systematically review published studies which estimate the reported point prevalence of major mental illness, alcohol and substance misuse at the time of assessment, and that of homelessness on committal in Irish prisoners.

\section{Aims}

To systematically analyse published data pertaining to three questions:

a. What is the reported point prevalence of psychotic illness and major affective disorder in Irish prisoners?

b. What is the reported point prevalence of alcohol or substance misuse disorder in Irish prisoners?

c. What was the reported point prevalence of homelessness on committal in Irish prisoners?

\section{Methods}

PRISMA Guidelines (Moher et al. 2009) were followed in the conduct of this review. A research librarian (ID) conducted searches of PsycINFO, MEDLINE, PubMed, EMBASE and Google Scholar (1 January 1966 to 31 December 2016) for publications citing Irish data (Republic of Ireland) on point prevalence of major mental illness, substance misuse/dependence and homelessness amongst prisoners using the search terms 'mental*, psych $^{*}$, prevalence, disorder, prison ${ }^{*}$, substance $^{*}$, alcohol, drug*, misuse, dependen*, abuse, home*, nfa, no fixed abode, prison*, inmate, jail, sentenced, remand, detainee' and also combinations of those. 
We additionally searched websites of the Irish Prison Reform Trust, Mental Health Commission, Irish Prison Service and the Council of Europe. We augmented searches by reviewing research repositories including Lenus (a repository specific to the Irish health service), Scopus and reviewing governmental reports.

As overarching general inclusion criteria, studies were required to (1) be drawn from the general prison population, (2) relate to adult (>18 years) males and/or females in an Irish prison, and (3) cite quantitative data with a clear numerator and denominator.

Additional specific inclusion/exclusion criteria included:

1. For the purpose of this study, 'major mental Illness' included psychosis (schizophrenia, schizoaffective disorder, delusional disorder, psychotic depression, mania with psychosis, drug-induced psychosis) and affective disorder (major depressive disorder, bipolar affective disorder). Inclusion required the use of standardised diagnostic classification and/or psychiatric assessment. Studies based solely on selfreported symptoms were excluded, as were those drawn from select prison subpopulations (Giblin et al. 2012) and hospitalisation samples (O'Connor \& O'Neill 1990; Linehan et al. 2002). Data on point prevalence were extracted, as opposed to lifetime prevalence. Therefore, samples reporting historical diagnoses based on retrospective chart review (Davoren et al. 2015) were excluded.

2. Studies on substance misuse and alcohol misuse were included where diagnoses were made using a standardised diagnostic classification and/or psychiatric assessment. For the purpose of this study, 'misuse' was defined as harmful use or dependence. Studies based solely on self-reported symptoms or drug testing (Long, 2008) were excluded, as were those drawn from prison subpopulations such as hospitalisation samples or screened sub samples where the screening tool used did not target substance misuse (McInerney et al. 2013; O'Neill et al. 2016). Data on point prevalence were extracted, as opposed to lifetime prevalence (O'Mahony, 1997). Therefore, samples reporting historical diagnoses based on retrospective chart review (Davoren et al. 2015) were excluded.

3. For the purpose of this study, homelessness was defined as included those living 'homeless and roofless' and in 'unsettled accommodation'. Data on homelessness at the time of incarceration were extracted, as opposed to a lifetime history of homelessness. Studies drawn from prison subpopulations such as screened samples where the screening tool used did not assess homelessness (McInerney et al.
2013; O'Neill et al. 2016) and hospitalisation samples were excluded.

Data were independently extracted by two researchers (G.G., a Consultant Psychiatrist and N.K., a Senior Registrar in Psychiatry) for each included publication. There was no disagreement in data extracted by the two researchers.

\section{Statistical analysis}

For each outcome (psychosis, affective disorder, alcohol use, substance use, homelessness upon committal) a proportion meta-analysis was conducted to calculate the pooled percentage of prisoners who were suffering from each outcome. Inconsistency was measured across studies using the $I^{2}$ statistic, which reflects the percentage of variability in effect estimates due to heterogeneity, rather than sampling error; $30-60 \%$ is considered moderate levels of heterogeneity, 50-90\% substantial heterogeneity and $75-100 \%$ considerable heterogeneity (Higgins \& Green, 2011). Heterogeneity in meta-analysis refers to when the true effects being evaluated differ between studies. If the variation between the studies' results is above that expected by chance, there is evidence of heterogeneity. The Cochrane $\mathrm{Q}$ test was used to test heterogeneity, where random effects models were used where there was evidence of significant heterogeneity and fixed effects models where there was no evidence of significant heterogeneity. Meta-analysis calculations were performed and graphical plots were created using the StatsDirect software.

\section{Study quality}

For each included study, the quality of the study was assessed using the adapted Newcastle-Ottawa scale (Wells et al. 2014). This is a commonly used quality assessment tool for non-randomised studies including case control and cohort designs. It has previously been adapted to use in cross-sectional studies (Herzog et al. 2013). However, due to the lack of validation for crosssectional studies, we have used this as a descriptive indicator of study quality and not in statistical weighting.

\section{Results}

We reviewed 408 abstracts of which inclusion criteria were met for eight, six and five studies reporting the prevalence of major mental illness, substance misuse and homelessness on committal, respectively (Fig. 1). Study quality is reported using the adapted Newcastle-Ottawa scale in Table 1. Based on the evidence of significant heterogeneity in our review, random effects models were used for proportion meta-analyses. 

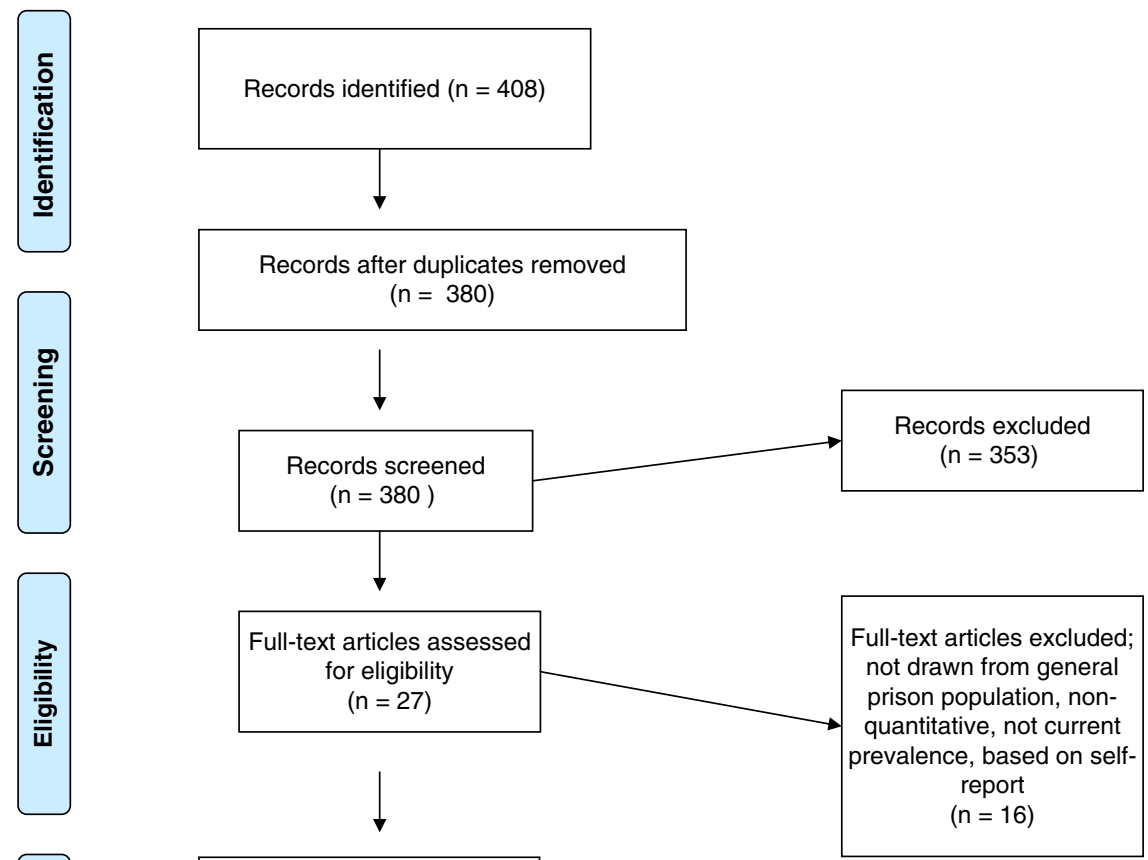

Studies included in in quantitative synthesis (metaanalysis) $\left(\mathrm{n}=11^{*}\right)$

For mental illness, $(n=8)$ For substance misuse, $(n=6)$ For homelessness, $(n=5)$ ( ${ }^{*}$ Included studies with one or more outcome of interest)

Fig. 1. Study inclusion flowchart.

Table 1. Study quality assessment (adapted Newcastle-Ottawa Scale)

\begin{tabular}{|c|c|c|c|c|c|}
\hline Studies & Year & Psychosis & Affective disorder & Substance misuse & Homelessness on committal \\
\hline Smith et al. & 1996 & 5 & 5 & 5 & - \\
\hline Mohan et al. & 1997 & 6 & 6 & 6 & - \\
\hline Seymour \& Costello & 2005 & - & - & - & 5 \\
\hline Linehan et al. & 2005 & 8 & 8 & 8 & 5 \\
\hline Duffy et al. & 2006 & 8 & 8 & 8 & 5 \\
\hline Wright et al. & 2006 & 7 & 7 & 7 & 5 \\
\hline Curtin et al. & 2009 & 7 & 7 & 7 & - \\
\hline McInerney et al. & 2013 & 7 & - & - & - \\
\hline Davoren et al. & 2015 & - & - & - & 5 \\
\hline O'Neill et al. & 2016 & 7 & 7 & - & - \\
\hline
\end{tabular}

Legend for rating: representativeness of sample $(0-1)+$ sample size $(0-1)+$ non-respondents $(0-1)+$ use of validated tool $(0-2)+$ assessment of outcome $(0-2)+$ statistical methods $(0-1)$, maximum score $=8$.

\section{Psychotic disorder}

Eight studies, with a total sample size of 28012 prisoners, reported suffering from a psychotic disorder (Table 2). The pooled percentage suffering from a psychotic disorder, from a random effects model, was
$3.6 \%(95 \% \mathrm{CI}=3.0-4.2 \%)$ (Fig. 2a). There was substantial heterogeneity in the percentage of prisoners diagnosed with a psychotic disorder across studies $\left(I^{2}=54.8 \%\right.$; Cochran's Q $\left.p=0.03\right)$.

The prevalence in male samples was $3.81 \%$ $(n=1060 / 27781)$. Only two studies (Mohan et al. 1997; 
Table 2. Prevalence of psychotic disorder

\begin{tabular}{|c|c|c|c|c|c|c|c|c|}
\hline Studies & Year & Location & Diagnostic criteria & $\%$ male & $\begin{array}{c}\text { Remand/ } \\
\text { sentenced/mixed }\end{array}$ & $n$ (psychosis) & $\begin{array}{c}N \\
\text { (total) }\end{array}$ & $\begin{array}{c}\text { Prevalence } \\
(95 \% \text { CI })(\%)\end{array}$ \\
\hline Smith et al. & 1996 & Mountjoy & DSM III R & 100 & Mixed & 9 & 235 & $3.8(1.8,7.1)$ \\
\hline Mohan et al. & 1997 & Dochas & DSM IV & 0 & Mixed & 1 & 45 & $2.2(0.1,11.8)$ \\
\hline Linehan et al. & 2005 & $\begin{array}{l}\text { Cloverhill, other } \\
\text { remand centres }\end{array}$ & ICD 10/DSM III R & 100 & Remand & 10 & 232 & $4.3(2.1,7.8)$ \\
\hline Duffy et al. & 2006 & Multiple prisons & DSM IV/ ICD 10 & 100 & Sentenced & 7 & 438 & $1.6(0.6,3.3)$ \\
\hline Wright et al. & 2006 & Dochas, Limerick & ICD 10 & 0 & Mixed & 8 & 186 & $4.3(1.9,8.3)$ \\
\hline Curtin et al. & 2009 & Mountjoy, Cloverhill & ICD 10 & 100 & Mixed & 13 & 615 & $2.1(1.1,3.6)$ \\
\hline McInerney et al. & 2013 & Cloverhill & ICD 10 & 100 & Remand & 766 & 20084 & $3.8(3.6,4.1)$ \\
\hline $\mathrm{O}^{\prime}$ Neill et al. & 2016 & Cloverhill & ICD 10 & 100 & Remand & 255 & 6177 & $4.1(3.6,4.7)$ \\
\hline Total & & & & & & 1069 & 28012 & $3.6(3.0,4.2)$ \\
\hline
\end{tabular}

$\mathrm{CI}=$ confidence interval; DSM = Diagnostic and Statistical Manual of Mental Disorders; $\mathrm{ICD}=$ International Classification of Disease.

Wright et al. 2006) evaluated prevalence in a purely female sample and estimates for females were $3.9 \%(n=9 / 231)$. Estimates of prevalence in purely remand samples could be extracted from four studies (Linehan et al. 2005; Curtin et al. 2009; McInerney et al. 2013; O'Neill et al. 2016) and were $3.9 \%(n=1043 / 26806)$.

\section{Major affective disorder}

Seven studies, with a total sample size of 7928 prisoners, reported an affective disorder (Table 3 ). The pooled percentage suffering from an affective disorder, from a random effects model, was $4.3 \%(95 \% \mathrm{CI}=2.1-7.1 \%)$ (Fig. 2b). There was considerable heterogeneity in the percentage diagnosed with an affective disorder across studies $\left(I^{2}=91.9 \%\right.$; Cochran's $\left.\mathrm{Q} p<0.001\right)$.

Prevalence from male samples was $2.33 \%(n=180 /$ 7697). Only two studies (Mohan et al. 1997; Wright et al. 2006) evaluated prevalence in a purely female sample and estimates for females were 9.1\% $(n=21 /$ 231). Estimates of prevalence in purely remand samples could be extracted from two studies (Linehan et al. 2005; O'Neill et al. 2016) and were 2.1\% $(n=134 / 6409)$.

\section{Alcohol and substance use disorders}

Six studies, with a total sample size of 1659 prisoners, reported alcohol or substance use disorders (Table 4). The pooled percentage suffering from alcohol disorder across the six studies, from a random effects model, was $28.3 \%$ (95\% CI $=19.9-37.4 \%$ ) (Fig. 2c). There was considerable heterogeneity in the percentage suffering from alcohol use disorder across studies $\left(I^{2}=92.9 \%\right.$; Cochran's $\mathrm{Q} p<0.0001)$. The pooled percentage of prisoners reporting a substance use disorder across the studies, from a random effects model, was 50.9\% (95\% CI $=37.6-64.2 \%$ ) (Fig. $2 \mathrm{~d}$ ). There was considerable heterogeneity in the percentage suffering from substance use disorder across studies $\left(I^{2}=96.4 \%\right.$, Cochran's Q $p<0.001)$.

Prevalence in male only samples was $37.1 \%(n=564$ / 1520) for alcohol use disorder and $51 \%(n=775 / 1520)$ for substance use disorder. Two studies (Mohan et al. 1997; Wright et al. 2006) evaluated prevalence in a purely female sample and estimates for females were $17.2 \% \quad(n=24 / 139)$ for alcohol use disorder and $62.6 \%(n=87 / 139)$ for substance use disorder. Estimates of prevalence in purely remand samples could be extracted from only one study (Linehan et al. 2005) and were $34.5 \%(n=80 / 232)$ for alcohol use disorder and 53\% $(n=123 / 232)$ for substance use disorder.

\section{Homelessness on committal}

Five studies, with a total sample size of 1523 prisoners reported homelessness at time of committal (Table 5). The pooled percentage of homelessness from a random effects model was $17.4 \%$ (95\% CI $=8.7-28.4 \%$ ) (Fig. 2e). There was considerable heterogeneity in the percentage of homelessness in comital across studies $\left(I^{2}=96.2 \%\right.$; Cochran's Q $p<0.001)$.

Prevalence in purely male samples was $8.2 \%(n=55 /$ 670). Only one study (Wright et al. 2006) evaluated prevalence in a purely female sample and estimates for females were $18.8 \%(n=35 / 186)$. Estimates of prevalence in purely remand samples could be extracted from two studies (Linehan et al. 2005; Davoren et al. 2015) and were $23.2 \%(n=153 / 658)$.

\section{Discussion}

Prisoners can experience a range of barriers to successful re-entry into society (Sarma, 2014). Homelessness, mental illness and substance misuse are three such barriers, which our study shows as being prevalent in Irish prisons. To our knowledge, this is the first 
(a)

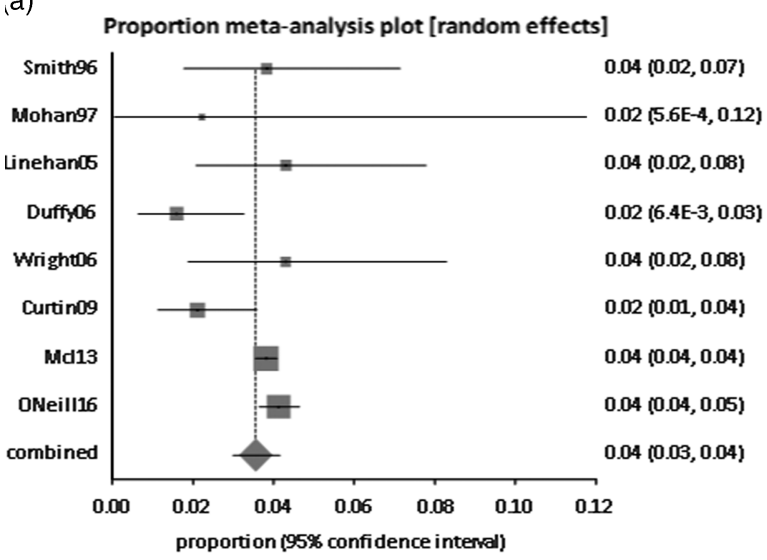

(c)
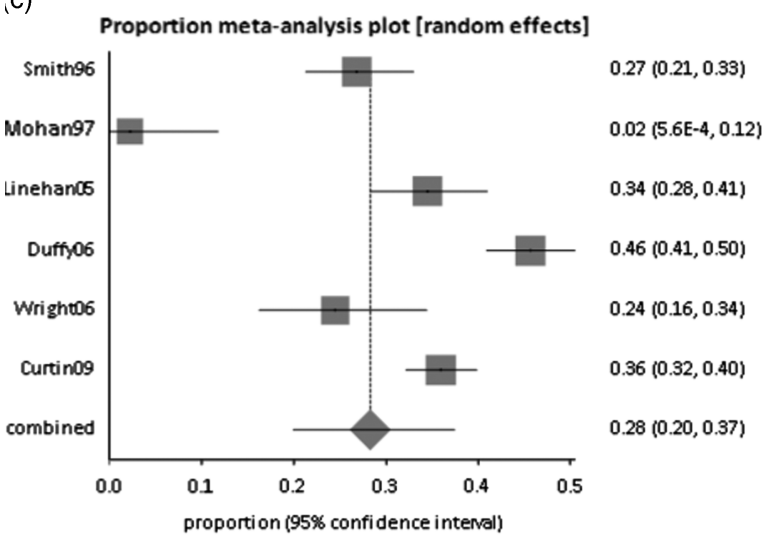

(b)

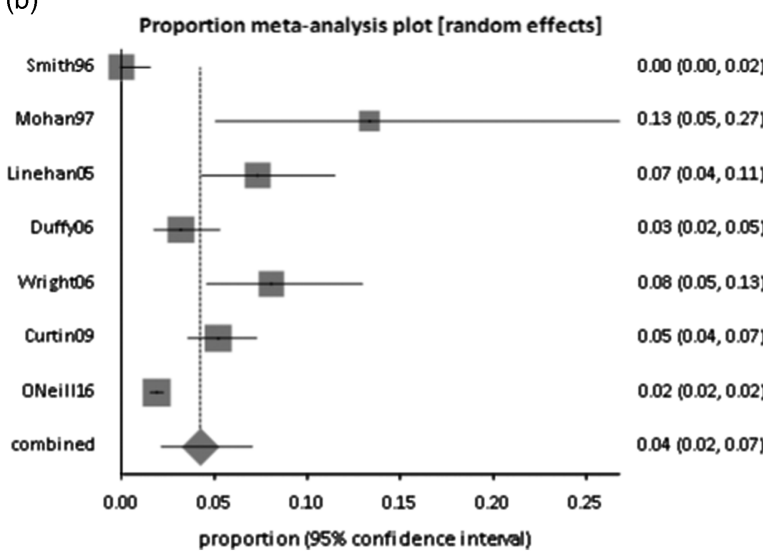

(d)

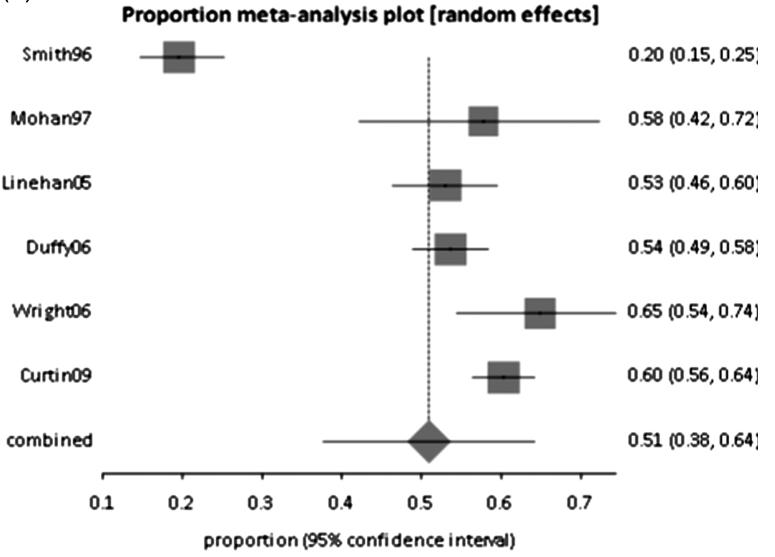

(e)

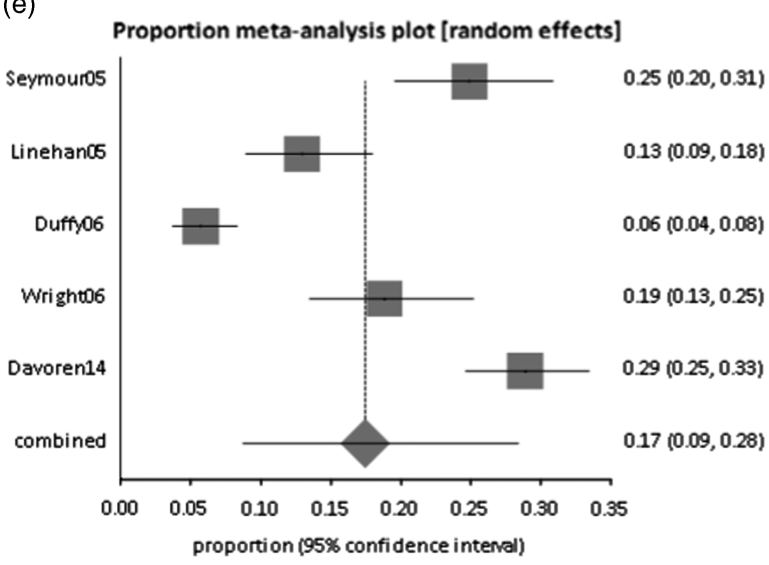

Fig. 2. Forest plot of studies with prisoners (a) diagnosed with a psychotic disorder, $(b)$ diagnosed with an affective disorder, $(c)$ diagnosed with an alcohol use disorder, $(d)$ diagnosed with a substance use disorder and $(e)$ homeless on committal.

systematic review estimating the current prevalence of these vulnerabilities amongst Irish prisoners.

\section{Implications}

A number of implications arise from these findings. This study confirms that a significant proportion of Irish prisoners present with a current psychotic or major affective disorder, which are potentially treatable mental illnesses. From a clinical view point, effective treatment of mental illness may reduce morbidity as well as potentially reduce mortality through suicide (Kapur, 2009), and potentially impact recidivism rates (Lovell et al. 2002). This finding strengthens the argument for the development of diversion services which, to date, are geographically variable and still evolving in Ireland (Gulati \& Kelly, 2018). Ireland has the lowest 
Table 3. Prevalence of major affective disorder

\begin{tabular}{|c|c|c|c|c|c|c|c|c|}
\hline Studies & Year & Location & Diagnostic criteria & $\%$ male & $\begin{array}{l}\text { Remand/ } \\
\text { sentenced/mixed }\end{array}$ & $n$ (affective) & $N$ (total) & $\begin{array}{l}\text { Prevalence } \\
(95 \% \text { CI })(\%)\end{array}$ \\
\hline Smith et al. & 1996 & Mountjoy & DSM III R & 100 & Mixed & 0 & 235 & $0(0,1.6)$ \\
\hline Mohan et al. & 1997 & Dochas & DSM IV & 0 & Mixed & 6 & 45 & $13.3(5.1,26.8)$ \\
\hline Linehan et al. & 2005 & $\begin{array}{l}\text { Cloverhill, other } \\
\text { remand centres }\end{array}$ & İCD 10/DSM III R & 100 & Remand & 17 & 232 & $7.3(4.3,11.5)$ \\
\hline Duffy et al. & 2006 & Multiple prisons & DSM IV/ ICD 10 & 100 & Sentenced & 14 & 438 & $3.2(1.8,5.3)$ \\
\hline Wright et al. & 2006 & Dochas, Limerick & ICD 10 & 0 & Mixed & 15 & 186 & $8.1(4.6,13.0)$ \\
\hline Curtin et al. & 2009 & Mountjoy, Cloverhill & ICD 10 & 100 & Mixed & 32 & 615 & $5.2(3.6,7.3)$ \\
\hline O'Neill et al. & 2016 & Cloverhill & ICD 10 & 100 & Remand & 117 & 6177 & $1.9(1.6,2.3)$ \\
\hline Total & & & & & & 201 & 7928 & $4.3(2.1,7.1)$ \\
\hline
\end{tabular}

$\mathrm{CI}=$ confidence interval; DSM = Diagnostic and Statistical Manual of Mental Disorders; ICD = International Classification of Disease.

Table 4. Prevalence of alcohol and substance use disorders

\begin{tabular}{|c|c|c|c|c|c|c|c|c|c|c|}
\hline Studies & Year & Location & $\begin{array}{l}\text { Diagnostic } \\
\text { criteria }\end{array}$ & $\begin{array}{c}\% \\
\text { male }\end{array}$ & $\begin{array}{l}\text { Remand/ } \\
\text { sentenced/ } \\
\text { mixed }\end{array}$ & $\begin{array}{c}n \\
\text { (alcohol) }\end{array}$ & $\begin{array}{c}n \\
\text { (substance) }\end{array}$ & $\begin{array}{c}N \\
\text { (sample) }\end{array}$ & $\begin{array}{l}\text { Prevalence } \\
(95 \% \text { CI) for } \\
\text { alcohol (\%) }\end{array}$ & $\begin{array}{c}\text { Prevalence } \\
\text { ( } 95 \% \text { CI) for } \\
\text { substance }(\%)\end{array}$ \\
\hline Smith et al. & 1996 & $\begin{array}{l}\text { Mountjoy } \\
\text { Prison }\end{array}$ & DSM III R & 100 & Mixed & 63 & 46 & 235 & $26.8(21.3,33.0)$ & $19.6(14.7,25.2)$ \\
\hline Mohan et al. & 1997 & $\begin{array}{l}\text { Mountjoy } \\
\text { Women's } \\
\text { Prison }\end{array}$ & DSM IV & 0 & Mixed & 1 & 26 & 45 & $2.2(0.1,11.8)$ & $57.8(42.2,72.3)$ \\
\hline Linehan et al. & 2005 & $\begin{array}{l}\text { Cloverhill, } \\
\text { other } \\
\text { remand } \\
\text { centres }\end{array}$ & $\begin{array}{l}\text { ICD 10/ } \\
\text { DSM IV }\end{array}$ & 100 & Remand & 80 & 123 & 232 & $34.5(28.4,41.0)$ & $53.0(46.4,59.6)$ \\
\hline Duffy et al. & 2006 & $\begin{array}{l}\text { Multiple } \\
\text { prisons }\end{array}$ & $\begin{array}{r}\text { DSM IV/ } \\
\text { ICD } 10\end{array}$ & 100 & Sentenced & 200 & 235 & 438 & $45.7(40.9,50.5)$ & $53.7(48.9,58.4)$ \\
\hline Wright et al. & 2006 & $\begin{array}{l}\text { Dochas, } \\
\text { Limerick }\end{array}$ & ICD 10 & 0 & Mixed & 23 & 61 & 94 & $24.5(16.2,34.4)$ & $64.9(54.4,74.5)$ \\
\hline Curtin et al. & 2009 & $\begin{array}{l}\text { Mountjoy, } \\
\text { Cloverhill }\end{array}$ & ICD 10 & 100 & Mixed & 221 & 371 & 615 & $35.9(32.1,39.9)$ & $60.3(56.3,64.2)$ \\
\hline Total & & & & & & 588 & 862 & 1659 & $28.3(19.9,37.4)$ & $50.9(37.6,64.2)$ \\
\hline
\end{tabular}

$\mathrm{CI}=$ confidence interval; DSM = Diagnostic and Statistical Manual of Mental Disorders; $\mathrm{ICD}=$ International Classification of Disease.

per capita secure psychiatric bed availability in developed countries (Kennedy, 2016). Diversion services need an expansion of bed capacity within Irish mental health services (Kennedy, 2006; Gulati \& Kelly, 2018) and changes in attitudes towards mentally disordered offenders (Duffy et al. 2003). Rates for psychotic disorders are in keeping with international estimates of prison morbidity (Fazel \& Seewald, 2012), which are significantly higher than general population estimates (Saha et al. 2005).

Rates for affective disorders in our study were higher, as would be expected in purely female samples, but low for remand samples in Ireland. The overall rates were lower than international comparisons and this may be due to the skewing of results based on one study where no prisoner was found to be suffering from a major affective disorder (Smith et al. 1996) or the use of point prevalence estimates in our study as opposed to period prevalence estimates in international comparisons. However, this would not explain why the rates in remand samples were low and may inform the need to review whether current screening processes for affective disorder in remand prisons (Grubin et al. 2002) are adequate.

The burden of harmful use or dependence on alcohol and substances in Irish prisons is substantial. One in three prisoners had a current alcohol misuse or dependence and one in two, a problem with current substance misuse or dependence. This is in keeping with international prison estimates (Fazel et al. 2006) and substantially higher than Irish general population estimates (Irish Medical Organisation, 2015). Substance and alcohol misuse are seen as key risk factors for recidivism. Prison and probation services have invested in 
Table 5. Prevalence of homelessness on committal

\begin{tabular}{|c|c|c|c|c|c|c|c|c|}
\hline Studies & Year & Location & $\begin{array}{l}\text { Diagnostic } \\
\text { criteria }\end{array}$ & $\%$ male & $\begin{array}{l}\text { Remand/ } \\
\text { sentenced/ } \\
\text { mixed }\end{array}$ & $\begin{array}{c}n \\
\text { (Homeless) }\end{array}$ & $\begin{array}{c}N \\
\text { (total) }\end{array}$ & $\begin{array}{l}\text { Prevalence } \\
(95 \% \text { CI) (\%) }\end{array}$ \\
\hline $\begin{array}{c}\text { Seymour \& } \\
\text { Costello }\end{array}$ & 2005 & $\begin{array}{l}\text { Multiple Dublin } \\
\text { prisons }\end{array}$ & Survey & 95 & Mixed & 60 & 241 & $24.9(19.6,30.9)$ \\
\hline Linehan et al. & 2005 & $\begin{array}{l}\text { Cloverhill and other } \\
\text { remand centres }\end{array}$ & $\begin{array}{l}\text { Semi-structured } \\
\text { interview }\end{array}$ & 100 & Remand & 30 & 232 & $12.9(8.9,17.9)$ \\
\hline Duffy et al. & 2006 & Multiple prisons & $\begin{array}{l}\text { Semi-structured } \\
\text { interview }\end{array}$ & 100 & Sentenced & 25 & 438 & $5.7(3.7,8.3)$ \\
\hline Wright et al. & 2006 & Dochas, Limerick & $\begin{array}{l}\text { Semi-structured } \\
\text { interview }\end{array}$ & 0 & Mixed & 35 & 186 & $18.8(13.5,25.2)$ \\
\hline Davoren et al. & 2015 & Cloverhill Dochas & $\begin{array}{l}\text { Retrospective } \\
\text { record review }\end{array}$ & 74 & Remand & 123 & 426 & $28.9(24.6,33.4)$ \\
\hline Total & & & & & & 273 & 1523 & $17.4(8.7,28.4)$ \\
\hline
\end{tabular}

$\mathrm{CI}=$ confidence interval

treatment programmes, but availability remains variable geographically. In the Irish context, treatment programmes for women, those specific to alcohol misuse as well as those focussed on novel drugs of misuse are seen as gaps in provision (Clarke \& Eustace, 2016). The cooccurrence of severe mental illness and substance use or abuse disorder are common (Buckley, 2006) with causes including self-medication, genetic vulnerability or lifestyle. The consequences include self-neglect, poor physical health, poor medication adherence, increased suicide risk and increased recidivism. There may be value in integrated treatment plans for that address both the addiction disorder and the mental illness (Minkoff, 1989).

Our study found that over one in six Irish prisoners is homeless at the point of committal. This is higher than prison estimates in the United States (Hughes et al. 2001; Greenberg \& Rosenheck, 2008) but only slightly higher than a comparative UK prison estimate (Williams et al. 2012). However, it is significantly higher than the prevalence of homelessness in the general Irish population (Central Statistics Office, 2016). McCann (2003) concluded that homelessness was both a cause and consequence of imprisonment. Hickey (2002) qualitatively studied the experience of ex-offenders. Nearly half of those participating in Hickey's study highlighted homelessness as one of the key contributory factors leading them to re-offend on release. Recidivism rates in Ireland are often used as a proxy for the success of rehabilitation programmes (Martynowicz \& Quigley, 2010). Analysing data relating to over 19000 prisoners in Ireland, O'Donnell et al. (2008) found that $49.2 \%$ of prisoners were re-imprisoned within 4 years with $27.4 \%$ within the first year. Addressing homelessness would potentially impact recidivism and imprisonment rates over and above the obvious humanitarian impact.
The coexistence of severe mental illness, substance misuse and homelessness has been studied in international literature (Drake et al. 1991) and these often go hand in hand, interacting in ways that amplify the vulnerability of an individual. Homeless individuals with mental illness are unlikely to seek help and treatment, and those that also have an active substance misuse often excluded from temporary accommodation, with the consequent further social decline and increased risk of imprisonment. It would follow that efforts to find suitable accommodation through resettlement services should be undertaken in conjunction with treatment of mental illness and/or substance misuse in prisoners.

In summary, the extent of psychiatric and psychosocial morbidity in worldwide prisons is of international concern as they are significantly higher than general population prevalence. Our review found that levels of psychiatric and psychosocial morbidity in Irish prisons are largely in keeping with worldwide prison estimates, and recommends improved screening for affective disorders, the development of diversion services and the consideration of integrated treatment plans addressing the psychiatric and psychosocial need.

\section{Strengths and limitations}

The strengths of this review include the search criteria which led to the identification of multiple samples for each outcome of interest within a relatively small jurisdiction.

The key limitation of this study is the high level of heterogeneity. While pooled prevalences are reported, and random effects model used to account for heterogeneity, we recommend interpreting these results with caution. Such a high level of heterogeneity would be expected in such a study in view of differences in study 
designs, study periods, sampling, diagnostic criteria (International Classification of Disease $v$. Diagnostic and Statistical Manual of Mental Disorders), category of prisoners (remand $v$. sentenced $v$. mixed) and gender differences, as has been seen in previous meta-analyses (Fazel \& Seewald, 2012). Furthermore, two included studies (McInerney et al. 2013; O'Neill et al. 2016) used case ascertainment through screening. In McInerney et al.'s study (2013), screening consisted of selecting all committals who on reception disclosed a history of previous psychiatric contact or prescription of psychiatric medication, a history of deliberate self-harm, who exhibited unusual or disturbed behaviour, those charged with homicide and individuals with a known history of treatment by prison psychiatric services. In O'Neill et al.'s study (2016), this was undertaken using the Grubin screening tool questions (Grubin et al. 2002) which has a reported sensitivity and specificity of $97 \%$ and $84 \%$, respectively, in a UK sample. The use of screening for case ascertainment has the potential to bias prevalence estimates.

Future research may usefully be aimed at re-evaluating point prevalence of these vulnerabilities through an up to date nationwide cross-sectional study with robust study design and standardised outcome measures to limit heterogeneity.

\section{Acknowledgements}

The authors would like to thank Dr Anna Zornoza, St Hugh's College, University of Oxford, Dr Valerie Murphy, University College Cork and Professor Ailish Hannigan, University of Limerick for their assistance.

\section{Financial Support}

This research received no specific grant from any funding agency, commercial or not-for-profit sectors.

\section{Conflicts of Interest}

All authors have no conflicts of interest.

\section{Ethical Standards}

The authors assert that all procedures contributing to this work comply with the ethical standards of the relevant national and institutional committee on human experimentation with the Helsinki Declaration of 1975 , as revised in 2008. The authors assert that ethical approval for publication of this paper was not required by their local REC.

\section{References}

American Psychiatric Association (1987). Diagnostic and Statistical Manual of Mental Disorders (3rd rev edn). American Psychiatric Association: Washington, DC.
Buckley PF (2006). Prevalence and consequences of the dual diagnosis of substance abuse and severe mental illness. Journal of Clinical Psychiatry 67 (Suppl. 7): 5-9.

Central Statistics Office (2016). Census of population 2016 profile 5 homeless persons in Ireland. CSO: Dublin (http:/ / www.cso.ie/en/releasesandpublications/ep/p-cp5hpi/ cp5hpi/hpi/). Accessed 19 September 2017.

Clarke A, Eustace A (2016). Drug \& alcohol treatment services for adult offenders in prison and in the community. Eustace Patterson Ltd: Dublin (http://www.justice.ie/en/JELR/PS_ IPS_Probation_Review_of_treatment_for_offenders.pdf/Files/ PS_IPS_Probation_Review_of_treatment_for_offenders.pdf). Accessed 19 September 2017.

Council of Europe: Committee for the Prevention of Torture (2015). Report to the government of Ireland on the visit to Ireland carried out by the European committee for the prevention of torture and inhuman or degrading treatment or punishment (CPT) from 16 to 26 September 2014 (No. CPT/Inf (2015) 38). Council of Europe, Committee for the Prevention of Torture: Strasbourg (https://rm.coe.int/ CoERMPublicCommonSearchServices/DisplayDCTM Content?documentId=0900001680696c9a). Accessed 19 September 2017.

Curtin K, Monks S, Wright B, Duffy D, Linehan S, Kennedy HG (2009). Psychiatric morbidity in male remanded and sentenced committals to Irish prisons. Irish Journal of Psychological Medicine 26, 169-173.

Davoren M, Fitzpatrick M, Caddow F, Caddow M, O'Neill C, O'Neill H, Kennedy HG (2015). Older men and older women remand prisoners: mental illness, physical illness, offending patterns and needs. International Psychogeriatrics 27, 747-755.

Duffy D, Lenihan S, Kennedy HG (2003). Screening prisoners for mental disorders. Psychiatric Bulletin 27, 241-242.

Duffy D, Linehan S, Kennedy HG (2006). Psychiatric morbidity in the male sentenced Irish prisons population. Irish Journal of Psychological Medicine 23, 54-62.

Drake RE, Osher FC, Wallach MA (1991). Homelessness and dual diagnosis. American Psychologist 46, 1149-1158.

Fazel S, Bains P, Doll H (2006). Substance abuse and dependence in prisoners: a systematic review. Addiction 101, 181-191.

Fazel S, Danesh J (2002). Serious mental disorder in 23000 prisoners: a systematic review of 62 surveys. The Lancet 359, 545-550.

Fazel S, Grann M, Kling B, Hawton K (2011). Prison suicide in 12 countries: an ecological study of 861 suicides during 20032007. Social Psychiatry and Psychiatric Epidemiology 46, 191-195.

Fazel S, Hope T, O'Donnell I, Jacoby R (2001). Hidden psychiatric morbidity in elderly prisoners. The British Journal of Psychiatry 179, 535-539.

Fazel S, Khosla V, Doll H, Geddes J (2008). The prevalence of mental disorders among the homeless in Western countries: systematic review and meta-regression analysis. PLoS Medicine 5, e225.

Fazel S, Seewald K (2012). Severe mental illness in 33588 prisoners worldwide: systematic review and meta-regression analysis. The British Journal of Psychiatry 200, 364-373.

Ferrari AJ, Somerville AJ, Baxter AJ, Norman R, Patten SB, Vos T, Whiteford HA (2013). Global variation in the 
prevalence and incidence of major depressive disorder: a systematic review of the epidemiological literature. Psychological Medicine 43, 471-481.

Giblin Y, Kelly A, Kelly E, Kennedy HG, Mohan D (2012). Reducing the use of seclusion for mental disorder in a prison: implementing a high support unit in a prison using participant action research. International Journal of Mental Health Systems 6, 2.

Grann M, Fazel S (2004). Substance misuse and violent crime: Swedish population study. British Medical Journal 328, 1233-1234.

Greenberg GA, Rosenheck RA (2008). Jail incarceration, homelessness, and mental health: a national study. Psychiatric Services 59, 170-177.

Grubin D, Carson D, Parsons S (2002). Report on new prison reception health screening arrangements: the results of a pilot study in 10 prisons. Department of Psychiatry, University of Newcastle: Newcastle, NSW (http:/ /a1538.g.akamai.net/7/ 1538/13355/v001/homeoffice.download.akamai.com/13355/ Doc/1011/101112067.pdf). Accessed 19 September 2017.

Gulati G, Kelly BD (2018). Diversion of mentally ill offenders from the criminal justice system in Ireland: comparison with England and Wales. Irish Medical Journal, 111, 719.

Herzog R, Álvarez-Pasquin MJ, Díaz C, Del Barrio JL, Estrada JM, Gil Á (2013). Are healthcare workers' intentions to vaccinate related to their knowledge, beliefs and attitudes? A systematic review. BMC Public Health 13, 154.

Hickey C (2002). Crime \& homelessness. Focus Ireland and PACE: Dublin (http://www.paceorganisation.ie/wp-con). Accessed 19 September 2017.

Higgins JPT, Green S (2011). Cochrane Handbook for Systematic Reviews of Interventions Version 5.1.0 [updated March 2011]. The Cochrane Collaboration (www.cochranehandbook.org.tent/uploads/2015/09/crime-homelessness. pdf). Accessed 19 September 2017.

Hughes TA, Wilson DJ, Beck AJ (2001). Trends in state parole, 1990-2000. Bureau of Justice Statistics. Special Report (NCJ 184735). U.S. Department of Justice, Bureau of Justice Statistics: Washington, DC.

Irish Medical Organisation (2015). IMO position paper on addiction and dependency. Irish Medical Organisation: Dublin (http:/ / www.drugs.ie/resourcesfiles/ResearchDocs/ Ireland/2015/Addiction_and_Dependency_IMO_Position_ Paper.pdf). Accessed 18 September 2017.

Irish Penal Reform Trust (2017). Facts and figures (http:/ / www.iprt.ie/prison-facts-2). Accessed 19 September 2017.

Irish Prison Service (2015). Annual report 2015. Irish Prison Service: Longford (http:/ / www.irishprisons.ie/wp-content/ uploads/documents_pdf/12232-Irish-Prison-Service-Annual Report2015-v7-2.pdf). Accessed 19 September 2017.

Kapur N (2009). Health services and suicide prevention. Journal of Mental Health 18, 1-5.

Kennedy H (2016). Opinion: prisons now a dumping ground for mentally ill young men. The Irish Times, 18 May (https:/ /www.irishtimes.com/opinion/opinion-prisons-nowa-dumping-ground-for-mentally-ill-young-men-1.2651034). Accessed 2 August 2017.

Kennedy HG (2006). The future of forensic mental health services in Ireland. Irish Journal of Psychological Medicine 23, $45-46$.
Kessler RC, McGonagle KA, Zhao S, Nelson C, Hughes M, Eshleman S, Wittchen HU, Kendler KS. (1994). Lifetime and 12-month prevalence of DSM-III-R psychiatric disorders in the United States. Results from the National Comorbidity Survey. Archives of General Psychiatry 51, 8-19.

Linehan S, Duffy D, O'Neill C, Kennedy HG (2002). Irish travellers and forensic mental health. Irish Journal of Psychological Medicine 19, 76-77.

Linehan SA, Duffy DM, Wright B, Curtin K, Monks S, Kennedy HG (2005). Psychiatric morbidity in a crosssectional sample of male remanded prisoners. Irish Journal of Psychological Medicine 22, 128-132.

Long J (2008). Drug tests in Irish prisons. Drugnet Ireland 26, 22-23.

Lovell D, Gagliardi GJ, Peterson PD (2002). Recidivism and use of services among persons with mental illness after release from prison. Psychiatric Services 53, 1290-1296.

McCann L (2003). Prison and homelessness: from a cell to the street. Council for Research and Development: A Commission of the Irish Bishops' Conference, November 2003 (http:/ / www.iprt.ie/files/prisons_and_homelessness.pdf). Accessed 2 August 2017.

Martynowicz A, Quigley M (2010). "It's Like Stepping on a Landmine...": Reintegration of Prisoners in Ireland. Irish Penal Reform Trust: Dublin.

McInerney C, Davoren M, Flynn G, Mullins D, Fitzpatrick M, Caddow M, O'Neill C (2013). Implementing a court diversion and liaison scheme in a remand prison by systematic screening of new receptions: a 6 year participatory action research study of 20,084 consecutive male remands. International Journal of Mental Health Systems 7, 18.

McNiel DE, Binder RL, Robinson JC (2005). Incarceration associated with homelessness, mental disorder, and co-occurring substance abuse. Psychiatric Services 56, 840-846.

Minkoff K (1989). An integrated treatment model for dual diagnosis of psychosis and addiction. Psychiatric Services 40, 1031-1036.

Mohan D, Scully P, Collins C, Smith C (1997). Psychiatric disorder in an Irish female prison. Criminal Behaviour and Mental Health 7, 229-235.

Moher D, Liberati A, Tetzlaff J, Altman DG, The PRISMA Group (2009). Preferred reporting items for systematic reviews and meta-analyses: the PRISMA statement. PLoS Medicine 6, e1000097.

O'Connor A, O'Neill H (1990). Male prison transfers to the central mental hospital, a special hospital (1983-1988). Irish Journal of Psychological Medicine 7, 118-120.

O'Donnell I, Baumer EP, Hughes N (2008). Recidivism in the Republic of Ireland. Criminology E Criminal Justice 8, 123-146. O'Mahony P (1997). Mountjoy Prisoners: A Sociological and Criminological Profile. Stationery Office: Dublin.

O'Neill C, Smith D, Caddow M, Duffy F, Hickey P, Fitzpatrick M, Caddow F, Cronin T, Joynt M, Azvee Z, Gallagher B, Kehoe C, Maddock C, O'Keefe B, Brennan L, Davoren M, Owens E, Mullaney R, Keevans L, Maher R, Kennedy HG (2016). STRESS-testing clinical activity and outcomes for a combined prison in-reach and court liaison service: a 3-year observational study of 6177 consecutive 
male remands. International Journal of Mental Health Systems $10,67$.

Paulson G (2012). Closing the Asylums: Causes and Consequences of the Deinstitutionalization Movement. McFarland Publishers: Jefferson, NC.

Rehm J, Taylor B, Room R (2006). Global burden of disease from alcohol, illicit drugs and tobacco. Drug and Alcohol Review 25, 503-513.

Saha S, Chant D, Welham J, McGrath J (2005). A systematic review of the prevalence of schizophrenia. PLoS Medicine 2, e141.

Sarma K (2014). Evaluation of the Cork prison in-reach pilot project. Focus Ireland: Dublin (https: / / www.focusireland. ie/wp-content/uploads/2016/04/Sarma-2014-Prison-InreachCork.pdf). Accessed 15 July 2017.

Seymour M, Costello L (2005). A study of the number, profile and progression routes of homeless persons before the court and in custody. Department of Justice, Equality and Law Reform: Dublin (http://arrow.dit.ie/cgi/viewcontent.cgi? article $=1005 \&$ context $=$ cserrep). Accessed 2 August 2017.

Smith C, O'Neill H, Tobin J, Walshe D, Dooley E (1996). Mental disorders detected in an Irish prison sample. Criminal Behaviour and Mental Health 6, 177-183.
Walmsley R (2016). World Prison Population List, 11th edn. ICPR: London.

Wells G, Shea B, O'Connell J, Robertson J, Peterson V, Welch V, Losos M, Tugwell P. (2013). The NewcastleOttawa Scale (NOS) for assessing the quality of nonrandomised studies in meta-analysis (http:/ / www. ohri.ca/programs/clinical_epidemiology/oxfordasp). Accessed 2 August 2017.

Williams K, Poyser J, Hopkins K (2012). Accommodation, homelessness and reoffending of prisoners: results from the Surveying Prisoner Crime Reduction (SPCR) survey. Ministry of Justice: London (http:/ / www.antoniocasella. eu/nume/Williams_homelessness_march12.pdf). Accessed 17 September 2017.

World Health Organisation (1993). The ICD-10 Classification of Mental and Behavioural Disorders, 10th edn. World Health Organisation: Geneva.

Wright B, Duffy D, Curtin K, Linehan S, Monks S, Kennedy HG (2006). Psychiatric morbidity among women prisoners newly committed and amongst remanded and sentenced women in the Irish prison system. Irish Journal of Psychological Medicine 23, 47-53. 